\title{
CLINICAL AND EPIDEMIOLOGICAL CHARACTERISTICS OF PATIENTS DIAGNOSED WITH COVID-19 IN A TERTIARY CARE CENTER IN MEXICO CITY: A Prospective COHORT STUdY
}

Dear Editor:

We have read the paper entitled "Clinical and Epidemiological Characteristics of Patients Diagnosed with COVID-19 in a Tertiary Care Center in Mexico City: A Prospective Cohort Study" by Ortiz-Brizuela and colleagues $^{1}$, in the May-June issue of the Revista de Investigacion Clínica-Clinical and Translational Research, we would to make out some observations on the reported data.

According to table 1 of the article, if the number of obese subjects in the entire cohort is 67 out of 309 subjects, then the percentage of obesity is $21.6 \%$, and not $39.6 \%$ as stated, the same would apply to overweight subjects ( $21.6 \%$ ). Furthermore, in the inpatient cohort, the percentage of obese/ overweight subjects is once again overstated as $39.7 \%$ and $41.3 \%(n=50 / 52$ out of 140$)$, respectively, using these number the percentages would correspond to slightly lower figures $(35.7 \%$ and $37.1 \%)$. Finally, in the outpatient cohort, the reported subjects with obesity/overweight are $39.5 \%$ and $34.9 \%$, but with 17 and 15 subjects out of 169 individuals, the percentages should be far lower at $10 \%$ and $8.8 \%$, respectively.

Thus, the paper's conclusion that patients with COVID-19 diagnosis were obese or overweight is quite ambiguous and irrelevant as most of the cohort is not comprised by subjects with excessive weight (overweight or obese).

\section{REFERENCES}

1. Ortiz-Brizuela E, Villanueva-Reza, González-Lara MF, TamezTorres KM, Román-Montes CM, Díaz-Mejía BA, et al. Clinical

and epidemiological characteristics of patients diagnosed with COVID-19 in a tertiary care center in mexico city: a prospective cohort study. Rev Invest Clin. 2020;72:165-77.

\section{Carlos E. Mendez-Probst ${ }^{1 *}$, David Velazquez-Fernandez ${ }^{2}$, and Ricardo Castillejos-Molina ${ }^{1}$}

${ }^{1}$ Department of Urology and ${ }^{2}$ Surgery Division, Instituto Nacional de Ciencias Médicas y Nutrición Salvador Zubirán, Mexico City, Mexico

*Corresponding author:

Carlos E. Mendez-Probst

E-mail: probstmc@hotmail.com
Received for publication: 24-06-2020

Approved for publication: 30-06-2020

DOI: $10.24875 / R I C .20000301$

0034-8376 / (c) 2020 Revista de Investigación Clínica. Published by Permanyer. This is an open access article under the CC BY-NC-ND license (http://creativecommons.org/licenses/by-nc-nd/4.0/). 


\section{AUTHOR'S REPLY}

We appreciate the interest of Mendez-Probst and colleagues on our results recently published in Revista de Investigación Clínica - Clinical and Translational Investigation ${ }^{1}$. Although most relevant data in the study were prospectively collected, some information also was obtained from medical records. Hence, the possibility of missing data is a weakness of our study. Most of the missing information in table 1 concerns to the outpatient's group who were evaluated once in a triage room. Note that the number of valid observations for each binary variable can be easily deduced from the table using simple arithmetic operations (with the percentage and number of observations reported). For example, as stated in table 1 , dysgeusia

\section{REFERENCES}

1. Ortiz-Brizuela E, Villanueva-Reza, González-Lara MF, TamezTorres KM, Román-Montes CM, Díaz-Mejía BA, et al. Clinical

\section{Alfredo PonCe-De-León*}

Department of Infectious Diseases, Instituto Nacional de Ciencias Médicas y Nutrición Salvador Zubirán, Mexico City, Mexico

*Corresponding author:

Alfredo Ponce-de-León

E-mail: alf.poncedeleon@gmail.com was reported in $100 \%$ of outpatients, nevertheless, only one subject reported this symptom. Consequently, it can be easily inferred that this symptom was only assessed in one patient. However, considering Mendez-Probst et al. observation to interpret table 1, we provide new tables 1-3 in the Corrigendum section of this issue, detailing the number of valid observations for each variable. Moreover, we understand MendezProbst et al. concerns regarding the validity of the comparison between inpatients and outpatients due to amount of missing data. Consequently, we updated this comparison with our data recollected up to June 1 , and similar findings were found: a prevalence of overweight or obesity in $83 \%(671 / 808)$ and $49.4 \%$ (267/540), among inpatients and outpatients, respectively $(p<0.01)$ (unpublished data).

and epidemiological characteristics of patients diagnosed with COVID-19 in a tertiary care center in Mexico city: a prospective cohort study. Rev Invest Clin. 2020;72:165-77. 